\title{
LETTERS
}

\section{Evidence shows that cannabis has fewer relative harms than opioids}

In an article in CMAJ, Fitzcharles and colleagues ${ }^{1}$ raise a number of important concerns stemming from the need for more rigorous research into therapeutic applications of cannabinoids. Unfortunately, their arguments are undermined by their unsubstantiated claims about the relative risks of cannabis compared with opioids.

The authors acknowledge there are several symptoms and conditions for which cannabis has shown to be effective (e.g., severe childhood epilepsy, chemotherapyinduced nausea, palliation at end of life) and suggest that the evidence is not sufficient to support other conditions that are commonly thought to improve with cannabis, including chronic noncancer pain. This conclusion is debatable, especially in light of the recent consensus reached by the US National Academies of Sciences, Engineering, and Medicine that there is substantial evidence to support cannabinoids for the treatment of chronic pain. ${ }^{2}$ We take particular issue with the authors' assertions that the relative lower harms of cannabinoids as compared with opioids are merely public "perception" and that without more cannabis research, we may see "a potential disaster similar to the opioid epidemic in North America." 1

We agree that more high-quality research is needed on the possible health benefits and acute and chronic harms of cannabis use. We are one of many research groups in Canada planning or conducting experimental trials into cannabinoidbased therapies. However, suggesting that cannabis might spark a public health problem on the level of the current opioid overdose crisis is not supported by scientific evidence. Although cannabis use is neither risk free nor a panacea, the risks it poses of physical dependence and accidental overdose compared with opioid use are substantially lower - indeed, fatal overdose with cannabis has never been documented and is thought to be impossible. ${ }^{3}$ Especially in the era of the opioid overdose crisis, the common sequelae of opioid use disorder (e.g., fatal overdose, acquisition or transmission of blood-borne diseases) are hardly comparable to those of cannabis use disorder at either individual or population levels. The lower relative risks associated with cannabis are reflected in substantially lower rates of cannabisassociated morbidity, mortality and societal costs compared with opioids in Canada, despite much higher levels of exposure. ${ }^{4}$ Simply put: it is not perception that cannabis has fewer relative harms than opioids; it is evidence.

The authors' viewpoint also overlooks an emerging body of preliminary research (including some from controlled trials) describing beneficial relationships between cannabis use or access and rates of opioid use and related harms, including overdose. For example, population-level research from the United States has reported lower rates of opioid-related mortality, ${ }^{5}$ opioid analgesic dispensations, ${ }^{6,7}$ and opioid-related hospital admissions $^{8}$ in jurisdictions with licit access to medical cannabis. Multiple studies of people who use medical cannabis have documented both ad hoc and intentional reductions in opioid use, often in the context of chronic pain. ${ }^{9,10}$ Recent experimental trials in humans have shown that lower doses of opioids co-administered with cannabinoids achieved analgesia equivalent to higher doses of opioids, ${ }^{11}$ and administration of cannabidiol reduced cue-induced opioid craving among people with opioid use disorder. ${ }^{12}$ In our 3 prospective cohorts of people at high risk of opioid overdose in Vancouver, we have found a number of beneficial longitudinal associations with consistent cannabis use, such as superior engagement in opioid agonist therapies for opioid use disorder, ${ }^{13}$ reduced frequency of illicit opioid use in the context of chronic pain ${ }^{14}$ and lower rates of exposure to fentanyl. ${ }^{15}$

We strongly agree with the authors' views that governments, regulators and other stakeholders must support highquality independent research into cannabis in order to mitigate its harms and maximize its potential benefits. However, these clinical, public health and regulatory research priorities are likely to miss the mark without a clear-eyed and accurate appraisal of the existing scientific evidence on cannabinoids and human health however limited it may be.

\section{Stephanie Lake MSc}

PhD candidate and research associate, BC Centre on Substance Use; UBC School of Population and Public Health, Vancouver, $\mathrm{BC}$

\section{Eugenia Socías MD MSc}

Assistant professor and research scientist, UBC Department of Medicine; BC Centre on Substance Use, Vancouver, BC

\section{M.-J. Milloy PhD}

Canopy Growth professor of cannabis science and research scientist, UBC Department of Medicine; BC Centre on

Substance Use, Vancouver, BC

Cite as: CMAJ 2020 February 18;192:

E166-7. doi: 10.1503/cmaj.74120

\section{References}

1. Fitzcharles M-A, Shir Y, Häuser W. Medical cannabis: strengthening evidence in the face of hype and public pressure. CMAJ 2019;191:E907-8.

2. The health effects of cannabis and cannabinoids: the current state of evidence and recommendations for research. Washington (DC): National Academies of Sciences, Engineering, Medicine; 2017. Available: www.nationalacademies.org/hmd/Reports/2017/ health-effects-of-cannabis-and-cannabinoids.aspx (accessed 2017 January 31).

3. Iversen LL. The science of marijuana. 3rd ed. New York: Oxford University Press; 2018.

4. Canadian Substance Use Costs and Harms Scientific Working Group. Canadian substance use costs and harms (2007-2014). Ottawa: Canadian Centre on Substance Use and Addiction; 2018. Available: www.ccsa.ca/sites/default/files/2019-04/CSUCH -Canadian-Substance-Use-Costs-Harms-Report -2018-en.pdf (accessed 2019 Oct. 17).

5. Gladden RM, Martinez $P$, Seth P. Fentanyl law enforcement submissions and increases in synthetic opioid-involved overdose deaths -27 states, 2013-2014. MMWR Morb Mortal Wkly Rep 2016; 65:837-43.

6. Bachhuber MA, Saloner B, Cunningham CO, et al. Medical cannabis laws and opioid analgesic overdose mortality in the United States, 1999-2010. JAMA Intern Med 2014;174:1668-73.

7. Powell D, Pacula RL, Jacobson M. Do medical marijuana laws reduce addictions and deaths related to pain killers? J Health Econ 2018;58:29-42.

8. Shi Y. Medical marijuana policies and hospitalizations related to marijuana and opioid pain reliever. Drug Alcohol Depend 2017;173:144-50.

9. Boehnke KF, Litinas E, Clauw DJ. Medical cannabis use is associated with decreased opiate medication use in a retrospective cross-sectional survey of patients with chronic pain. J Pain 2016;17:739-44. 
10. Reiman A, Welty M, Solomon P. Cannabis as a substitute for opioid-based pain medication: patient self-report. Cannabis Cannabinoid Res 2017;2:160-6.

11. Bradford AC, Bradford WD, Abraham A, et al. Association between US state medical cannabis laws and opioid prescribing in the Medicare Part D population. JAMA Intern Med 2018;178:667-72.

12. Cooper ZD, Bedi G, Ramesh D, et al. Impact of co-administration of oxycodone and smoked cannabis on analgesia and abuse liability. Neuropsychopharmacology 2018;43:2046-55.

13. Hurd YL, Spriggs S, Alishayev J, et al. Cannabidiol for the reduction of cue-induced craving and anxiety in drug-abstinent individuals with heroin use disorder: a double-blind randomized placebocontrolled trial. Am J Psychiatry 2019;176:911-22.

14. Socías ME, Wood E, Lake S, et al. High-intensity cannabis use is associated with retention in opioid agonist treatment: a longitudinal analysis. Addiction 2018;113:2250-8.

15. Lake S, Walsh Z, Kerr T, et al. Frequency of cannabis and illicit opioid use among people who use drugs and report chronic pain: a longitudinal analysis. PLoS Med 16(11):e1002967.

Competing interests: The University of British Columbia has received an unstructured gift to support M.-J Milloy's research from NG Biomed, Ltd., an applicant to the Canadian federal government for a license to produce medical cannabis. Dr. Milloy is the Canopy Growth professor of cannabis science at UBC, a position created by an unstructured gift to the university from Canopy Growth, a licensed producer of cannabis, and the Government of British Columbia's Ministry of Mental Health and Addictions. No other competing interests were declared. 